\title{
Global Studies Consortium (Tenth meeting) 7 - 11 June, 2017 Shanghai University, China
}

\section{Retno Mustikawati}

Global Studies Ph.D student, Shanghai University, People Republic of China retnomustika7@gmail.com

Quoted Jan Nederveen Pieterse that occasionally one hears that 'one should never study something with the word "studies" in it'. The idea is that 'studies' lack the structure, depth and craft of the disciplines. If we consider the wide and growing array of studiesinternational studies, development studies, area studies, cultural studies, gender studies, black studies, ethnic studies, world system studies, postcolonialstudies, urban studies, border studies, media/communication/film studies, transnationalstudies, global studies, feminist studies, and so forth - they all concern new objects of study, domains, approaches or subjects and sensibilitiesthat did not exist or were not recognized at the time when the disciplines took shape, largely in the course of the nineteenth century. A discipline is a field of study (with a community of scholars, a distinctive terrain and principles or methods of research), so disciplines and studies are synonymous. The distinction runs essentially between early and latecomers, a matter of seniority. The early comers claim to be foundational while the latecomers claim new objects of study. The 'studies' often exist in an uneven (sometimes fraught) relationship with the disciplines because the new domains are also studied in the disciplines (e.g. sociology of culture) and broaden and rejuvenate the disciplines, and the 'studies' often break down according to the disciplines (such as development economics, development sociology, urban anthropology). The rationale of the emergence of 'studies' is that the disciplines are inadequate in relation to thefield of study which requires an interdisciplinary approach and/or that they involve agency and subjectivity which is marginalized in established academe, as in the case of women, minorities, and migrants. Unlike the disciplines, 'studies' lack a canon or there tends to be greater unevenness in what is recognized as expert knowledge, if only because of the relativen ewness of the field. Unlike the disciplines, the 'studies' lack a recognized place in academia, where the disciplines occupy the main arena and act as gatekeepers for newcomers.

Hence 'studies' are often introduced first at young or newcomer universities, which cannot compete with the established universities in the disciplines, but can try to establish themselves and attract faculty and students in new terrains. 
Global studies, then, shares several features with other 'studies' - global studies is new, interdisciplinary, uneven, and innovative. Its object of study is also researched in the disciplines, largely under the heading of globalization — a field that, arguably, has been colonized by the disciplines. Global studies, then, represents the third wave of research, because global knowledge and data exist prior to the category 'globalization'.

To facilitate the features sharing and to represent this third wave of research, the Global Studies Consortium (GSC) is established in 2007, at Santa Barbara, California. Member programs of the Global Studies Consortium are Aarhus University, Arizona State University, Berlin Graduate School for Transnational Studies, University of California at Santa Barbara, University of Leipzig Germany, London School of Economics and Political Science (United Kingdom), Economic History Department, Roskilde University (Denmark), Department of Society \& Globalization, University of Vienna (Austria), Department of History University of Wroclaw (Poland), Institute of International Studies, Hanyang University, Hitotsubashi University Japan, University of Illinois at UrbanaChampaign, University of Minnesota, Lomosonov Moscow State University, The New School University of North Carolina at Chapel Hill, University of Pittsburgh, RMIT University, Rutgers University-Newark, Shanghai University, Sophia University, Wilfrid Laurier University, Australian National University, The American University in Cairo, Shantou University, Ghent University, University of Graz, Monash University. The annual meetings are held every year since then. In 2017, it was held in Shanghai University.

\section{Global Studies Consortium Statement of Purpose}

In this critical moment in the life of universities around the world, academic programs have responded to the forces of globalization in creative ways, conducing to new graduate programs in global studies. The purposes of this consortium are to promote and facilitate graduate teaching programs in global studies and to foster cooperation among them. The consortium is open to any academic program in the world that offers a graduate M.A., M.Sc., M.Phil., or Ph.D. related to global studies. It also includes programs that are transnational, transcultural, global/local, world systems, or cross area, and that are hospitable to interdisciplinary and multidisciplinary approaches within the humanities and social sciences to global studies.

The tenth Global Studies Consortium in Shanghai was devided into two improtant meetings, The first half of the meeting, from 7 to 8 June, will be a research-oriented conference on the theme Asia to the Middle East : Asianization of Middle East with Economic, and The "core" portion of the Consortium meeting, covering GSCspecific issues and business, will take place on June 9 and 10. June 11 will be for social activities.

This report will be specifically focused on the "core" portion of the meeting, withein 9-10 June, 2017. The meeting's Co-chairs were : GUO Changgang (Shanghai University), Mark Juergensmeyer (Santa Barbara, California). Presenters: GUO Changgang (China); David Wank (Japan); Paul Battersby (Australia); Matthias Middell (Europe); Ilya Ilyin (Russia); Evelyn Davidheiser (N. America); Mahendra Lama (India/South Asia); ZHAO Wuming (respondent, Shantou University). 
On the Dayone / Friday June 9, Guo Changgang, the Dean of Global Studies Center, Shanghai University delivered his welcome speech, and followed by Mark Juergensmeyer . The opening plenary took place in the next two and a half hours, brought an important Global Studies Status Report, 2007-2017: Trends Across the Regions, as all the presenters were delivering their thoughts and ideas.

The next agenda was the Plenary Session, brought a focus of discussion about the Interdisciplinarity as a Research Framework in Global Studies, Vladimir Pacheco Cueva (chair, Aarhus); ZHAO Wuming (Shantou); Michael Goodhart (Pittsburgh); Jie-Hyun Lim (Sogang); Tommaso Durante (respondent, RMIT) were discussing about The field of Global Studies opens new ways of examining socio-economic, political and cultural phenomena that transcends the national, regional and area studies perspectives, yielding ground breaking studies that expose the connections between seemingly unrelated concepts or that show how local issues are reflected at the global level. The Plenary Session were devided into different issues:

\section{Panel 1: Internships and Service Learning: Beyond Study Abroad}

This panel allows global studies scholars to review past and current programs, and explore new trends and opportunities for global studies internship and service learning. Presentations are especially invited, but not limited, to engaging with transformation of traditional study abroad programs to address experiential learning practices and methodology covering the various aspects of global studies education, to discuss cultural, social and academic perspectives pertinent to different institutional locations and/or geographic regions, and challenges facing the development of global studies internship and service learning programs.

\section{Panel 2: Publication initiatives, editorial opportunities}

The session will be devoted primarily to a brief update on the new rollout of the global studies online journal global -e and editorial board roles available to Consortium participants, followed by a presentation by David Famiano, Journals Editor at the University of California Press, updating last year's presentation about the recently approved UC Press online journal platform Global Perspectives, and editorial and contributor opportunities for GSC scholars.

\section{Panel 3: Global Studies Curriculum Design: From Undergrad to Graduate}

Framing the Consortium's perennial topics of curriculum design and "foundational courses" in such a way as to engage new participants representing undergrad and graduate programs (as well as those only dreaming of one), this session discussed types of courses, intended outcomes in terms of student skills/knowledge from different types and their combination, and how these integrate with and meet the overarching themes or goals of the program. This panel included representatives of programs ranging from $\mathrm{BA}$ to $\mathrm{MA} / \mathrm{PhD}$. 


\section{Panel 4: Global Learning and Global Language Studies}

University academics generally fail to acknowledge the importance of multilingual knowledge and skills for the future careers of their graduates. This panel explores the role of language learning, teaching, and research in the context of the "global" education underway today in diverse settings, including contemporary entrepreneur-style universities. Discussion topics included among others the business and economic value and the political power of languages that are looking to drive today's education and global learning agenda.

On the Daytwo / Saturday June 10 of the consortium, the panel discussion was continued.

\section{Panel 5: Populist Movements and the Challenge for Global Studies}

This panel invites responses to the question: Is there a challenge to global studies when populist politicians or parties argue heavily against globalization, and if so how do you react to it with your program?

Then the Closing Plenary Discussion was focused on the next 10 years of Global Studies Consortium. On the daytwo, the consortium was closed by a farewell dinner in the evening. The last event was the sightseeing of Shanghai on Sunday, June 11.

By following and listening to the Global Studies Consortium, I came to the conclusion that Global Studies is closely related to looking at the same problems, globally, worldwide. In contrast to International Studies the more portion looks at the prevention of problems that occur in two or more countries, based on an agreement between two or more parties, based on bilateral or multilateral relations. Global studies, however, are at the opposite angle of International Studies, which is centralized in the concept of local and global connectivity, which often departs from a postcolonial perspective, and is intended to analyze the phenomena happening globally through critical multicultural lenses. Globalization as growing interconnectedness, thus a multilevel approach follows from the interdisciplinary character of global studies, for disciplines such as anthropology, sociology, geography, and history function at multiple social scales.

Unlike the International studies referred to as "right wing," Global studies are identified with the term of "left wing" when globalization has an impact that can no longer be contained throughout the world, and because national boundaries between countries are no longer relevant to tackling the impact of the wave of globalization which then leads to the dependency / relationship that must be built on the economic, social, cultural and human levels themselves. Global studies aspires to be more comprehensive than studies of globalization by combining diverse perspectives, new problematics and understandings. The new knowledge platforms take shape, so global studies has the potential to be more comprehensive and sophisticated than studies of globalization, which is driven by social science and humanities disciplines, while global studies are interdisciplinary. Global studies, then, refers to viewing global issues from diverse, multicentric perspectives and redefining international affairs accordingly. To the extent that it meets this standard, global studies is appropriate to a multipolar world and more relevant to contemporary dynamics than disciplinary approaches. Thus, the need to analyze critically on global issues can only be solved by conducting multicultural analyzes in the global world. 